\title{
TRATAMENTOS SUPERFICIAIS POR VIA ÚMIDA EM BIOMATERIAIS METÁLICOS
}

\author{
I. J. PERGHER ${ }^{1}$ e B. L. FERNANDES ${ }^{1}$ \\ ${ }^{1}$ Pontifícia Universidade Católica do Paraná, Curso de Engenharia Química \\ E-mail para contato: isabellapergher@hotmail.com
}

\begin{abstract}
RESUMO - Os biomateriais metálicos têm sido objeto de estudo, pois exercem várias funções como: substituir sistemas, órgãos ou tecidos na forma de próteses e como implantes. No entanto para entrarem em contato com os tecidos vivos precisam ser passivados, diminuindo a taxa de corrosão. No caso das ligas de titânio, o ataque ácido tem a função de eliminar contaminantes, homogeneizar a superfície e formar camadas de óxidos de titânio com diferentes espessuras. O tratamento por via úmida foi objeto de estudo desse trabalho, consistindo em avaliar a capacidade passivante do ácido cítrico, como alternativa ao ácido nítrico, validando os parâmetros usados para a passivação do aço ASTM F138. Para tanto, o tratamento superficial foi realizado na liga Ti6A14V ELI (ASTM F86) tendo como referência as normas técnicas ASTM A967/A967M (2013) e ASTM A380/A380M (2013). A barra da liga Ti6Al4V foi cortada em pastilhas que sofreram limpeza, decapagem e passivação seguindo as recomendações das normas. As superfícies foram avaliadas em microscópio ótico e em microscópio eletrônico de varredura, onde não ocorreu a formação de óxidos visíveis com os ácidos utilizados e, portanto, embora haja interesse pela indústria na substituição do ácido nítrico, os parâmetros de tratamentos atuais não podem ser usados no tratamento da liga Ti6A14V. A implicação imediata é a necessidade de estudos de processos de ataque com esses ácidos para as ligas de titânio, gerando parâmetros e novas normas técnicas.
\end{abstract}

\section{INTRODUÇÃO}

Os biomateriais exercem várias funções, como: substituir sistemas, órgãos ou tecidos, na forma de próteses e como implantes (SILVA, 2001). Para que os implantes não causem reações indesejáveis quando implantados no corpo humano, devem apresentar composição química e características superficiais adequadas. Apesar de considerados biocompatíveis, os biomateriais metálicos liberam partículas dentro do corpo humano que podem causar reações adversas indesejáveis. Para evitar a corrosão excessiva, os biomateriais metálicos passam pelo tratamento superficial de passivação antes de implantados (PIERETTI, 2012).

O titânio, puro ou ligado, é um dos metais mais usados na fabricação de implantes, pois é considerado quimicamente estável e altamente biocompatível. A sua alta resistência à corrosão, tornando-o especialmente atrativo para aplicações em implantes ortopédicos e dentários (OLIVEIRA, 1995). 
Na fabricação de implantes e próteses ortopédicas, devido à solicitação mecânica, a liga Ti6Al4V é a mais usada. As superfícies dos implantes, depois dos processos de conformação, possuem contaminantes e tensões superficiais, além de uma topografia não uniforme. Esta superfície não é apropriada para entrar em contato com os tecidos vivos e, por isso, tratamentos superficiais posteriores são realizados com a finalidade de se obter um acabamento superficial adequado (LAUSMAA, 2001).

Dentre os tratamentos superficiais realizados estão os de via úmida, que englobam: limpeza, ataque ácido, passivação e acabamento eletrolítico, padronizado pela norma técnica ASTM A380(2013) (LAUSMAA, 2001).

Com base no exposto, o objetivo do presente trabalho foi estudar a superfície da liga Ti6Al4V, depois de atacada por ácido cítrico, usando como referência os parâmetros preconizados pelas normas técnicas ASTM A967-13 e ASTM A380-13.

\section{MATERIAIS E MÉTODOS}

\subsection{Material}

Utilizou-se para o estudo uma barra metálica de $300 \mathrm{~mm}$ de comprimento e $10 \mathrm{~mm}$ de diâmetro da liga Ti6AI4V, da qual foram extraídos 50 corpos de prova (CDP) de 3,0 mm de espessura. Para os tratamentos superficiais foram utilizadas soluções de ácido nítrico e de ácido cítrico, em concentrações definidas para cada etapa, apresentadas nos próximos itens.

\subsection{Limpeza e Decapagem}

Os corpos de provas passaram por procedimentos de limpeza e decapagem de acordo com as recomendações das normas técnicas ASTM A967-13 e ASTM A380-13. Foram lixados e imersos em solução aquosa de detergente em $45^{\circ} \mathrm{C}$, em limpador ultrassônico por 15 min. O objetivo desta etapa foi remover graxas, óleos e outros contaminantes resultantes do processo de fabricação e de manuseio. Os resíduos do detergente foram retirados com lavagem com água destilada, e as peças foram novamente levadas ao limpador ultrassônico contendo etanol PA, onde permaneceram por mais $10 \mathrm{~min}$. Os CDP foram, então, retirados do banho, lavados com água deionizada e deixados para secar em estufa por $1 \mathrm{~h}$, sem que tivessem contato entre si.

Para a decapagem verteu-se $500 \mathrm{ml}$ de uma solução contendo $20 \%$ em volume de ácido nítrico e 3,5\% em volume de ácido fosfórico em um béquer de $1 \mathrm{~L}$ posicionado sobre um agitador magnético. Treze dos $50 \mathrm{CDP}$ foram imersos na solução que foi mantida em agitação por $25 \mathrm{~min}$. As peças foram movimentadas a cada $5 \mathrm{~min}$. para garantir o máximo de contato das superfícies com a solução. As peças foram, então, retiradas e posicionadas em uma peneira para lavagem com água deionizada para retirada do ácido e levadas para a estufa. Depois de secos, os corpos de prova foram reservados em dessecador com vácuo, até o início do processo de passivação. Esse procedimento foi repetido para mais três lotes de peças, até que todas tivessem sofrido o mesmo tratamento. 


\subsection{Passivação}

O processo de passivação realiza a remoção de ferro livre e de outros materiais contaminantes por meio de tratamento químico, criando uma superfície livre para a formação espontânea de camada de óxido protetor. Esta etapa foi realizada com o ataque de soluções de ácido nítrico e de ácido cítrico.

\subsubsection{Passivação com ácido nítrico}

As soluções contendo ácido nítrico $\left(\mathrm{HNO}_{3}\right)$ e ácido nítrico com dicromato de sódio $\left(\mathrm{Na}_{2} \mathrm{Cr}_{2} \mathrm{O}_{7}\right)$ estão apresentadas no Quadro 1.

Quadro 1: Soluções de Ácido Nítrico usadas no processo de passivação

\begin{tabular}{|c|c|c|c|c|}
\hline Solução & Qtde (ml) & Composto & $\begin{array}{c}\text { \%em } \\
\text { volume }\end{array}$ & $\begin{array}{c}\text { \% em } \\
\text { massa }\end{array}$ \\
\hline $1 \mathrm{~N}$ & 500 & $\mathrm{HNO}_{3}$ & 20 & -- \\
\cline { 3 - 5 } & & $\mathrm{Na}_{2} \mathrm{Cr}_{2} \mathrm{O}_{7}$ & -- & $2,5 \pm 0,5$ \\
\hline $2 \mathrm{~N}$ & 500 & $\mathrm{HNO}_{3}$ & 20 & -- \\
\hline $3 \mathrm{~N}$ & 500 & $\mathrm{HNO}_{3}$ & 20 & -- \\
\hline
\end{tabular}

Para cada uma das soluções, $500 \mathrm{ml}$ foram vertidos em um béquer de $1 \mathrm{~L}$ posicionado sobre um aquecedor com controle de temperatura e agitação magnética. Para cada uma foram tratados 6 CDP retirados do dessecador mantido em vácuo, com o auxílio de uma pinça para evitar contaminação. As diferenças entre os tratamentos foram a temperatura da solução e o tempo de imersão, de acordo com a Tabela 1. Para todas as soluções, a temperatura foi elevada até a adequada ao tratamento antes da imersão das peças e todas foram mantidas em agitação.

Tabela 1: Temperaturas e tempos das soluções usadas para a passivação de 24 CDP (6 para cada solução).

\begin{tabular}{ccc}
\hline Solução & Faixa de Temperatura $\left({ }^{\circ} \mathrm{C}\right)$ & Tempo $(\min )$ \\
\hline $1 \mathrm{~N}$ & $50-55$ & 20 \\
$2 \mathrm{~N}$ & $20-25$ & 30 \\
$3 \mathrm{~N}$ & $50-55$ & 20 \\
\hline
\end{tabular}

Depois do tempo de cada tratamento, as peças foram retiradas com pinças, posicionadas em uma peneira e lavadas imediatamente com água deionizada. Em seguida, foram imersas em $700 \mathrm{ml}$ de água destilada com pH entre 6,5 e 7,0 na temperatura ambiente, contido em um béquer de $1 \mathrm{~L}$ posicionado sobre um agitador magnético, a fim de parar o processo de passivação. Manteve-se a agitação por 5 min. e as peças retiradas foram mantidas em estufa. Depois de secas, foram identificadas $(1 \mathrm{~N}, 2 \mathrm{~N}$ e $3 \mathrm{~N})$ e novamente reservadas em dessecador com vácuo. 


\subsubsection{Passivação com ácido cítrico}

Para a passivação com ácido cítrico $\left(\mathrm{C}_{6} \mathrm{H}_{8} \mathrm{O}_{7}\right)$, utilizou-se $1,5 \mathrm{~L}$ da solução aquosa contendo $4 \%$ em massa do ácido, variando-se a temperatura do banho e o tempo de exposição da peça ao ácido, de acordo com a Tabela 2. O procedimento foi realizado em 3 lotes de peças (6 para cada lote): verteu-se $500 \mathrm{ml}$ da solução em um béquer de $1 \mathrm{~L}$ posicionado sobre um aquecedor com controle de temperatura e com agitação magnética. $\mathrm{O}$ banho foi aquecido até a temperatura de tratamento, a agitação ligada e as peças imersas.

Tabela 2: Temperaturas e tempos das soluções usadas para a passivação de 18 CDP (6 para cada solução)

\begin{tabular}{ccc}
\hline Solução & $\begin{array}{c}\text { Faixa de Temperatura } \\
\left({ }^{\circ} \mathrm{C}\right)\end{array}$ & Tempo (min) \\
\hline $1 \mathrm{C}$ & $60-65$ & 4 \\
$2 \mathrm{C}$ & $50-55$ & 10 \\
$3 \mathrm{C}$ & $20-25$ & 20 \\
\hline
\end{tabular}

Depois do tempo de cada tratamento, as peças foram retiradas com pinças e sofreram o mesmo tratamento realizado com as peças passivadas com $\mathrm{HNO}_{3}$, identificadas como $1 \mathrm{C}, 2 \mathrm{C}$ e $3 \mathrm{C}$, e reservadas em dessecador com vácuo. Oito dos $50 \mathrm{CDP}$ originais não sofreram passivação, ficando estocados em dessecador a vácuo para servirem como controle.

\subsection{Análise em Microscópio}

Os CDP foram cortados ao meio com uma cortadeira de precisão Struers, modelo Minitom, para visualização da camada de óxido formada em microscópio óptico (MO). Foram, então, embutidos a quente em resina acrílica, e preparadas de acordo com protocolo padrão de preparação de amostras metalográficas: lixamento sequencial com lixas mesh 220, 400, 600 e 1200, consecutivamente; polimento com pasta de alumina 0,1 $\mu \mathrm{m}$; lavagem e secagem com o auxílio de secador elétrico.

Depois de preparadas, as amostras (Figura1) com os tratamentos mais fortes 2C, 3C, $2 \mathrm{~N}$ e $3 \mathrm{~N}$, foram analisadas em MO com ampliação de $2.500 \times$ sem ataque químico e com ataque químico com solução Nital $2 \%\left(\mathrm{HNO}_{3} 2 \%\right.$ em volume e etanol $98 \%$ em volume) com imersão por $20 \mathrm{~s}$.

Figura 1: Peças prontas para análise em MO. Da esquerda para a direita: $2 \mathrm{C}, 3 \mathrm{C}, 2 \mathrm{~N}$ e $3 \mathrm{~N}$.

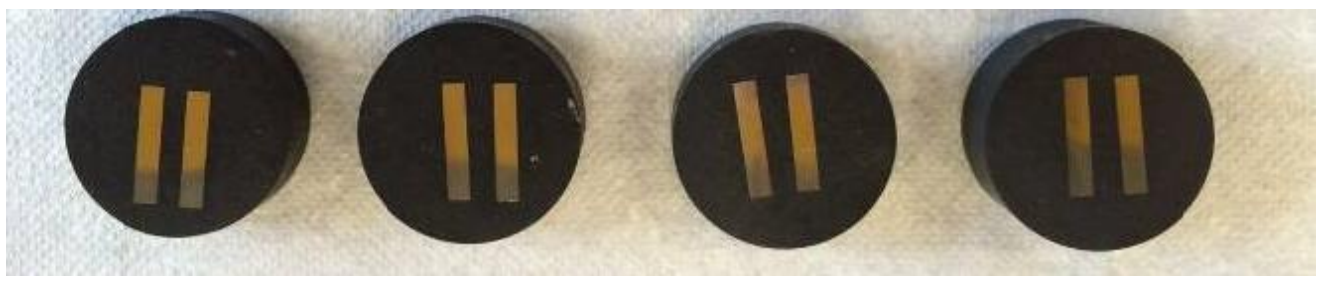


A análise em MO não mostrou camadas visíveis de óxidos. Como a resolução máxima era de $2.500 x$, não foi possível afirmar que não ocorreu a formação das camadas de óxidos. Desta forma, foi realizada a análise em microscopia eletrônica de varredura (MEV). Para tanto foram analisadas as mesmas amostras anteriormente analisadas em MO, com aumento de 5.000x.

\section{RESULTADOS E DISCUSSÃO}

A Figura 2A e 2B mostra as imagens do Microscópio Eletrônico de Varredura (MEV). Apresenta-se as análises das peças que foram passivadas com as maiores concentrações de cada ácido estudado (3C e $3 \mathrm{~N}$ ), pois não foram identificadas camadas de óxidos.

Figura 2: Parte superior formada pela resina e parte inferior pela liga Ti6Al4V. (A)

Morfologia do CDP passivado com 3N; (B) Morfologia do CDP passivado com 3C.
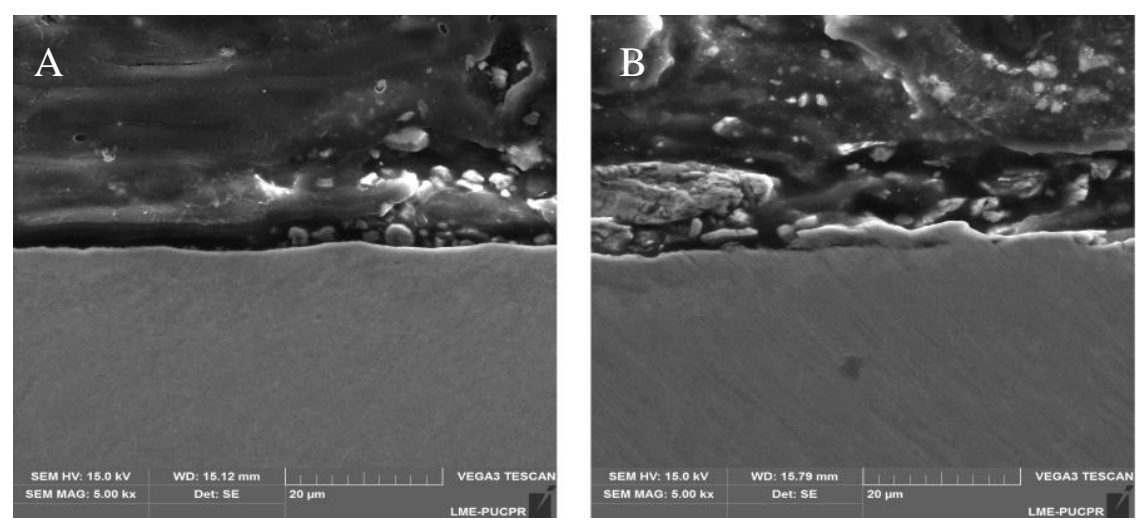

Analisando as imagens fornecidas pelo MEV e no aumento utilizado, pode-se verificar que não ocorreu a formação de camadas de óxidos para os ataques realizados. Dependendo da espessura, diferentes cores de filmes são visíveis (entre $10 \mathrm{~nm}$ e $80 \mathrm{~nm}$ ) (VELTEN et al., 2001). Nenhuma cor foi identificada, portanto, é possível inferir que as normas técnicas ASTM A967-13 e ASTM A380-13 não são adequadas para a formação da camada de óxidos adequada para a liga de titânio, ou seja, a concentração das soluções, a temperatura e tempo dos banhos, não foram suficientes para o ataque químico adequado.

Uma das principais causas para a não formação de óxidos é a maior estabilidade química da liga de titânio quando comparada com a dos aços, motivo pelo qual titânio e suas ligas são mais adequadas para a fabricação de próteses e implantes.

\section{CONCLUSÃO}

As indústrias voltadas à fabricação de implantes metálicos utilizam soluções com misturas de ácidos forte, geralmente, nítrico, fosfórico e sulfúrico, para o ataque superficial dos metais com a finalidade de obterem superfícies homogêneas e mais biocompatíveis. Apesar do interesse industrial na substituição desses ácidos nocivos por outros sustentáveis e atóxicos, o processo de ataque químico da liga Ti6Al4V realizado neste trabalho, mostrou ser ineficaz, sugerindo a inviabilidade das normas ASTM A967 e ASTM A380 para esta 
aplicação. Portanto, existe a necessidade de estudos com parâmetros diferentes daqueles apresentados pelas normas e a elaboração de norma técnica específica.

\section{REFERÊNCIAS}

A380/A380M-13 Standart Practice for Cleaning, Descaling, and Passivation of Stainless Steel Parts, Equipment and Systems.

A967/A967M-13 Standart Specification for Chemical Passivation Tretments for Stainless Steel Parts.

LAUSMA, J. Mechanical, Thermal, Chemical and Eletrochemical Surface Treatment of Titanium. Titanium in Medicine. Springer-Verlag: Berlim, 2001, Cap. 8, p.232-266.

SILVA, M.M. Modificação de propriedades superficiais da liga Ti-6Al-4V pelo processo implantação iônica por imersão em plasma. Instituto Tecnológico de Aeronáutica, São José dos Campos 2001. Disponível em: http://www.bd.bibl.ita.br/tde_busca/arquivo.php?codArquivo=2445>. Acesso em: 25 de jan.2016.

PIERETTI, E.F. Efeito da marcação na resistência à corrosão de implantes ortopédicos produzidos em aço inoxidável. Instituto de Pesquisas Energéticas e Nucleares, São Paulo 2012.

Disponível em: http://pelicano.ipen.br/PosG30/TextoCompleto/Eurico\%20Felix\%20Pieretti_M.pdf>. Acesso em: 25 de jan. 2016.

OLIVEIRA, V. M. et al. Obtenção da liga Ti-6Al-7Nb para aplicação em próteses ortopédicas. In Congresso anual da ABM. 50, 1995, SP. Anais.

VELTEN, D. et al. Preparation of TiO2 layers on cp-Ti and Ti6Al4V by thermal and anodic oxidation and by sol-gel coating techniques and their characterization. J Biomed Mat Res, v.59, n1, 2001. 